\title{
Modeling of fine coal flotation separation based on particle characteristics and hydrodynamic conditions
}

\author{
B. Shahbazi ${ }^{1} \cdot$ S. Chehreh Chelgani ${ }^{2}$
}

Received: 10 February 2016/Revised: 11 September 2016/Accepted: 11 October 2016/Published online: 21 October 2016

(C) The Author(s) 2016. This article is published with open access at Springerlink.com

\begin{abstract}
Flotation is a complex multifaceted process that is widely used for the separation of finely ground minerals. The theory of froth flotation is complex and is not completely understood. This fact has been brought many monitoring challenges in a coal processing plant. To solve those challenges, it is important to understand the effect of different parameters on the fine particle separation, and control flotation performance for a particular system. This study is going to indicate the effect of various parameters (particle characteristics and hydrodynamic conditions) on coal flotation responses (flotation rate constant and recovery) by different modeling techniques. A comprehensive coal flotation database was prepared for the statistical and soft computing methods. Statistical factors were used for variable selections. Results were in a good agreement with recent theoretical flotation investigations. Computational models accurately can estimate flotation rate constant and coal recovery (correlation coefficient 0.85 , and 0.99 , respectively). According to the results, it can be concluded that the soft computing models can overcome the complexity of process and be used as an expert system to control, and optimize parameters of coal flotation process.
\end{abstract}

Keywords Coal processing $\cdot$ Flotation $\cdot$ Modeling $\cdot$ Particle characteristics $\cdot$ Hydrodynamic conditions

\section{Introduction}

Global consumption of primary energy continues to grow. Especially coal demand has increased from 2013 hence China has started to import the heating coal. Coal is domestically the largest source of energy in America, and demands to generate electricity and to produce high grade coking coal have made the process of fine coal $(-500 \mu \mathrm{m})$ reasonable. These facts have emphasized on the

Electronic supplementary material The online version of this article (doi:10.1007/s40789-016-0147-9) contains supplementary material, which is available to authorized users.

S. Chehreh Chelgani

schehreh@umich.edu

1 Department of Mining Engineering, Tarbiat Modares University, Tehran, Iran

2 Department of Electrical Engineering and Computer Science, University of Michigan, Ann Arbor, MI 48109, USA development of technologies that can produce clean fine coal particles to reduce their environmental problems (Sun and Zimmerman 1950). To treat fine coal particles, the well-established technique is froth flotation. Flotation is a physicochemical separation method which is undoubtedly the most important and versatile mineral processing technique for the beneficiation of fine valuable particles (Wills 2006; Jena et al. 2008; Abkhoshk et al. 2010).

Coal flotation is the most efficient method to improve the quality of fine particles by reducing impurity contents (ash, mineral matter and sulfur resources) (Tao et al. 2002; Gupta et al. 2009; Barraza et al. 2013; Gui et al. 2014). Separation by flotation is a complex three-phase process (liquid, solid and air phases) with many sub-processes and interactions. Flotation of coal samples is controlled by many factors that divided into three parts: coal, chemistry and machine (Wills 2006; Huynh et al. 2011; Liang et al. 2015; Peng et al. 2015).

Generally, flotation is based on differences of the coal and impurities surface chemical characteristics. Coal is a 
heterogeneous material which composed of a variety of organic (different organic components (macerals) of coal may respond differently to flotation) and inorganic constituents (Lynch et al. 1981; Hower et al. 1984; Arnold and Aplan 1989; Hower et al. 2000). Therefore, surface properties and flotation response of coal samples are significantly varied, and it is important to understand how different factors affect and how to control coal flotation performance for a particular system (Huynh et al. 2011). It is well established that conducting a model for the process would be beneficial to fully understand mechanisms of various units (Woodbum et al. 1976; King 1978; Woodbum and Wallin 1984; Mathe et al. 2000; Abkhoshk et al. 2010). Main benefits of these models could be: the control and improvement of the flotation process. Development of an applicable flotation model also could lead to the generation of a simulator that can be used to optimize the process, train plant operators and engineers, help to the better understanding of the complex three-phase phenomenon, and scale up of laboratory test results (Sherrell 2004; Do 2010).

To provide an accurate flotation model, the effect of hydrodynamic parameters on the flotation response of coarse and fine minerals has been widely investigated and a few studies have modeled recovery in empirical ways (Shahbazi and Rezai 2009; Shahbazi et al. 2012; Shahbazi et al. 2013a, b). The main limitation of those models is their applicability over widely varying feed characteristics (Rra et al. 1989). Also several fundamental flotation models which have taken many parameters into account were designed, but these models did not widely apply in industrial flotation studies (due to their complexity and the variety of immeasurable parameters) (Amini 2012). The complication of flotation mechanism and interdependence of micro processes have been made evaluation and generation of quantitative and predictive model significantly difficult (Sherrell 2004; Do 2010; Amini 2012; Golshani et al. 2013; Karimi et al. 2014).

Recent reviews on modeling methods reported that the number of soft computing based engineering models is increasing (Dote and Ovaska 2001). Soft computing is a collection of methodologies including fuzzy system, neural networks, and genetic algorithm which developed to eliminate imprecision and uncertainty of a nonlinear complex system (Kayak and Zadeh 1998). One of the popular soft computing methods is the neuro-fuzzy technique that is a hybrid combination of artificial neural networks (ANN) and fuzzy inference system (FIS). Adaptive neuro-fuzzy inference system (ANFIS) is an example of a neuro-fuzzy technique. ANFIS introduces a neural network (NN) approach in fuzzy inference system design (Jang 1993; Jang and Sun 1995; Jang et al. 1997). ANFIS has been applied in many aspects of mineral processing to model complex relationships (For flotation, ANFIS is applied to the prediction of collision probability, recovery, gas holdup, diameter, and surface area flux of bubbles) (Jorjani et al. 2008, 2009; Chelgani et al. 2010, 2011a, b; Chelgani and Makaremi 2013; Shahbazi et al. 2013a, b).

In this study, to better understand the association of various parameters during coal flotation, the effect of particle characteristics and hydrodynamic conditions was investigated for a wide size fraction of coal particles. Statistical analyses have been used to explore inter-correlation and relationship among flotation parameters and responses to select the most effective variables for the modeling. This investigation also is going to present an accurate method for the prediction of flotation responses (recovery and flotation rate constant) based on the selected hydrodynamic parameters and particle properties by using ANFIS models. To our knowledge, this is the first time that ANFIS has been used to predict coal flotation responses using an inclusive database of the mentioned input variables.

\section{Materials and methods}

\subsection{Froth flotation}

An applicable computing model requires a comprehensive database to cover a wide variety of conditions. The model should be capable for predicting outputs with a high validity. Evaluation of effective variables in the process usually is accomplished by fitting batch data to first-order kinetic rate equations (Loveday and Raghubir 1995; Runge et al. 1997; Harris 1998; Agar et al. 1998). In this study, the data was produced by flotation tests that conducted in a mechanical laboratory cell (the length: 0.13 and height $0.12 \mathrm{~m}, 1.5 \mathrm{l})$. An impeller with $0.07 \mathrm{~m}$ diameter was used for the pulp agitation. The impeller's rotational speed were $900,1000,1100$, and $1200 \mathrm{rpm}$, and the air flow rate were varied from 120 to $180 \mathrm{l} / \mathrm{h}$. Coal samples were prepared from Abnil mine in Kerman, southeast of Iran (Table 1). Samples were classified to eight size classes: -37 , $-53+37,-75+53, \quad-106+75, \quad-212+106$, $-300+212,-420+300$ and $-500+420 \mu \mathrm{m}$ and were used for flotation experiments. 22.4 ppm MIBC (methyl iso-butyl carbinol) as a frother was added to the mixture.

The batch wise flotation of coal particles can be described by the following first order rate equation in which the removal rate of particles is given by:

$\frac{\mathrm{dC}_{\mathrm{t}}}{\mathrm{d} t}=-k C_{t}$

$R=R^{*}\left(1-\exp ^{-k t}\right)$

where, $C_{t}$ is the concentration of particle (mass per unit volume), $R^{*}$ is the infinite recovery (Do 2010; Shahbazi et al. 2013a, b; Soni 2013; Karimi et al. 2014), and $k$ is a 
Table 1 Proximate analysis of the Abnil coal sample (Air dried, \%)

\begin{tabular}{llllllll}
\hline Calorific value $(\mathrm{kcal} / \mathrm{kg})$ & Ash & $\mathrm{H}$ & $\mathrm{C}$ & $\mathrm{S}$ & $\mathrm{N}$ & Moisture & Volatile mater \\
\hline $6500-7000$ & 19.32 & 3.4 & 75.4 & 1 & 1.7 & 1.05 & 15.1 \\
\hline
\end{tabular}

"rate constant". Value $k$ can be calculated by plotting the first order rate equation for a batch cell [Eq. (2)] versus $t$. Flotation rate constant $(k)$ is strongly related to the $S_{\mathrm{b}}$ (bubble surface area flux) (Gorain et al. 1997, 1998):

$k=\alpha R_{\mathrm{f}} S_{\mathrm{b}}$

$S_{\mathrm{b}}=6 \frac{J_{\mathrm{g}}}{d_{32}}$

where $d_{32}$ is the sauter mean diameter of the bubble, $\alpha$ is the "floatability factor", $J_{\mathrm{g}}$ is the superficial gas velocity and $R_{\mathrm{f}}$ is the froth recovery factor. $R_{\mathrm{f}}$ is defined as the ratio of the overall flotation rate constant and the collection zone rate constant (Gorain et al. 1998; Hernandez-Aguilar et al. 2005). The $\alpha$ factor is affected by particle characteristics and hydrodynamic conditions during flotation (Shahbazi et al. 2012; Shahbazi et al. 2014).

Energy dissipation $(\dot{\varepsilon})$ and bubble Reynolds number $\left(R e_{\mathrm{b}}\right)$ are effective hydrodynamic parameters on the $k$ value (Nguyen 1998; Hu et al. 2003). The mean dissipation ( $(\varepsilon)$ in a stirrer can be calculated based on the following equation (Nguyen 1998)

$\varepsilon=\frac{P}{m}$

where $P$ is power input, and $\mathrm{m}$ is liquid mass. The energy flux equals to the dissipation. In other words, the power per unit mass of fluid is withdrawn from the basic flow and transformed into heat by the deceleration of the smallest vortices (Ralston et al. 1999). The particle Reynolds number is given by (Neethling and Cilliers 2003)

$R e_{\mathrm{p}}=\frac{d_{\mathrm{p}} u_{\mathrm{s}}}{v}$

where $u_{\mathrm{s}}$ is the rate of sliding motion for particles that is obtained by the particle settling rate. When $R e_{\mathrm{p}}<1$, a boundary layer with laminar flow is formed between the particle and fluid. When $R e_{\mathrm{p}}>1$, the flow condition becomes more turbulent. When $R e_{\mathrm{p}}>10$, the boundary layer breaks off. The flow lines near the coarse particle will curl up to form definite vortices. In the flotation tests, bubble Reynolds numbers " $R e_{\mathrm{b}}$ " were varied from 130 to 307.

Turbulence plays a decisive part in the flotation process (it is responsible for collisions between particles and bubbles), and in the formation of aggregates (for the stability of the aggregates in the greater part of the machine volume) (Schubert 1977). The intensity and the structure of the micro turbulence depend only on the magnitude of energy flux and the viscosity of the fluid. The energy flux is equal to the dissipation. In other words, the power per unit mass of fluid is withdrawn from the basic flow, and transforms into heat by the deceleration of the smallest vortices (Ralston et al. 1999). The micro scale turbulence $\left(\lambda_{0}\right)$ is calculated by the following equation (Schulze 1984a, b):

$\lambda_{0}=\left(\frac{v^{3}}{\varepsilon}\right)^{1 / 4}$

where $v$ is kinematic viscosity. To calculate bubble surface area flux $\left(S_{\mathrm{b}}\right)$ (based on Eq. (4)), the bubble size $\left(d_{\mathrm{b}}\right)$ distribution was measured in a device similar to the McGill's bubble viewer (Girgin et al. 2006). It consisted of a sampling tube attached to a viewing chamber with a window inclined at $15^{\circ}$ from vertical. The closed assembly was filled with water of a similar composition to the flotation cell (to limit errors in the bubble environment during the sampling). Then the tube was immersed in the desired location under the froth. Bubbles rose into the viewing chamber and were imaged by a digital camera. They slid up the inclined window which was illuminated from the behind. For this measurement, at first frother was added to the water and then the viewing chamber was filled with water of the cell to prevent bubble coalescence. Deviation between micro scale turbulence size and particle size $\left(\lambda_{0}-d \mathrm{p}\right)$ is effective on flotation response. Also, superficial gas velocity $\left(J_{g}\right)$ was calculated using the air flow rate and the area cross section of the cell with consideration of the area occupied by the impeller shaft. The input power was inferred from the electrical measurements; measuring the entrance amperage and voltage to the electrical motor of the flotation equipment. To calculate the net power consumption, at first power consumption of the equipment was measured by wattmeter (in absent of pulp), then flotation cell was filled by pulp, and power consumption was measured again. Net power consumption was calculated by subtraction of these two measured powers.

When the $S_{\mathrm{b}}$ value was constant, various size fractions were floated together in the same condition. In all experiments, the froth depth was shallow and the froth recovery factor $\left(R_{\mathrm{f}}\right)$ was assumed to be 1 . The air flow rate and the impeller speed were set and the float product was collected at interval times of: 1, 2, 3 and $5 \mathrm{~min}$. The recovery, $R$, was determined as a function of time $\left(R^{*}\right.$ calculated via the 
relative weight concentrate to feed "yield"), and the $k$ was calculated according to Eq. (2). Flotation results based on different conditions are presented in the database (supplementary database).

\subsection{Soft computing}

Fuzzy systems and neural networks are popular techniques (in recent decade, interest to these methods has been significantly increased. Both methodologies belong to the soft computing area and have simulated to be used for the human tolerance in completeness, uncertainty, imprecision and fuzziness in the decision making processes. Neural network and fuzzy logic are model-free estimators and share the common ability to deal with the uncertainties and noise (Yager and Zadeh 1994). Both of them encode the information in parallel and distribute architectures in a numerical framework. Hence, it is possible to convert fuzzy logic architecture to a neural network and vice versa. This fact makes it possible to combine the advantages of neural network and fuzzy logic. The ANFIS combines these two approaches (neural networks and fuzzy systems). Combining these two intelligent approaches lead to the increase in quality of modeling. In other words, both fuzzy reasoning and network calculation will be available simultaneously (Shoorehdeli et al. 2009). ANFIS is a method based on considered input-output data for a system. The main advantage of ANFIS is that it is one of the best tradeoffs between neural and FS which provides smoothness (due to the fuzzy control interpolation), and adaptability (due to the NN back propagation). Moreover, ANFIS has strong computational complexity restrictions (Atkinson 1989; Bastian 2000). Success in obtaining a reliable and robust ANFIS network heavily depends on the choice of involved process variables, the available data set, and the domain used for training purposes (Buragohain and Mahanta 2008). In this study, statistical analyses (SPSS software package) were applied in the comprehensive flotation database to choose the most effective variables on coal flotation responses (Recovery and rate constant), and for computational modeling ANFIS, MATLAB software package was used.

\section{Results and discussion}

\subsection{Effects of various variables on coal recovery}

According to the flotation test results (Fig. 1), recovery of coal particles increased with the increasing of $S_{\mathrm{b}}$ (till $S_{\mathrm{b}}$ reaches 27.43). After this point, flotation recovery is decreased. Results also indicated that for $\lambda_{0}$ $-d_{\mathrm{p}}<-300 \mu \mathrm{m}$, flotation recovery was minimum. The decreasing of recovery can be explained by the high efficiency of bubble-particle detachment. For $\lambda_{0}$ $-d_{\mathrm{p}} \sim-200 \mu \mathrm{m}$, a sharp increase in the recovery can be observed. In this condition, maximum recovery was obtained $(100 \%)$ when $S_{\mathrm{b}}$ was $20.191 / \mathrm{s}$. For $\lambda_{0}$ $-d_{\mathrm{p}}=0 \mu \mathrm{m}$, coal recovery was medium for all tests, and for $\lambda_{0}-d_{\mathrm{p}} \sim 100 \mu \mathrm{m}$, a significant decrease in recovery can be due to low efficiency of bubble-particle collision. For maximum $\lambda_{0}-d_{\mathrm{p}}$, a notable increase of recovery can be observed which can be due to entrainment of fine coal particles.

\subsection{Effects of various variables on flotation rate constant}

Based on the results (Fig. 2) when $\lambda_{0}-d_{\mathrm{p}}=0 \mu \mathrm{m}$, flotation $k$ was minimum. $k$ increased by increasing $\left|\lambda_{0^{-}} d_{\mathrm{p}}\right|$. Maximum real $k$ (flotation without entrainment) was 2.91 $1 /$ min when $S_{\mathrm{b}}$ was $19.081 / \mathrm{s}$ and $\lambda_{0}-d_{\mathrm{p}}$ was $-223 \mu \mathrm{m}$. Other variables did not show a significant effect on flotation rate constant.

\subsection{Statistical analysis}

To find the most effective variables for the modeling, intercorrelation have been used to explore and make relationship among all variables and flotation responses. Intercorrelation is a term used to denote the correlation of a number of variables among themselves, as distinct from the correlations between them and an 'output' or a dependent variable. The correlation between two variables reflects the degree to which the variables are related. The most common measure of correlation is the Pearson Product Moment Correlation (called Pearson's correlation for short " $r$ "). $r$ (inter-correlation) is a measure of linear association between two variables. $r$ values range from -1 to +1 . The sign of the correlation indicates the direction of the relationship, and its absolute value indicates the strength, with larger absolute values indicating stronger relationships. A negative value for the correlation implies a negative or inverse association, where a positive value means a positive association (SPSS 2004).

Results (Table 2) indicate that there is approximately the same absolute $\mathrm{r}$ value between $\mathrm{R}$ with $R e_{\mathrm{p}}, \lambda_{0}-d_{\mathrm{p}}$ and $d_{\mathrm{p}}(r:-0.58,0.61$ and -0.60 , respectively). Also there is a strong correlation between $R e_{\mathrm{p}}, \lambda_{0}-d_{\mathrm{p}}$ and $d_{\mathrm{p}}(r: 0.99)$ that was predictable based on Eq. (6) (Fig. 3). The same routine can be observed for the $k$, therefore; $d_{\mathrm{p}}$ was chosen as a representative parameter among particle character variables for the prediction of recovery and $k$. This evaluation is in a good agreement with recent investigations (Do 2010; Soni 2013) that concluded: "the flotation kinetics and hence the recovery varies depending on 

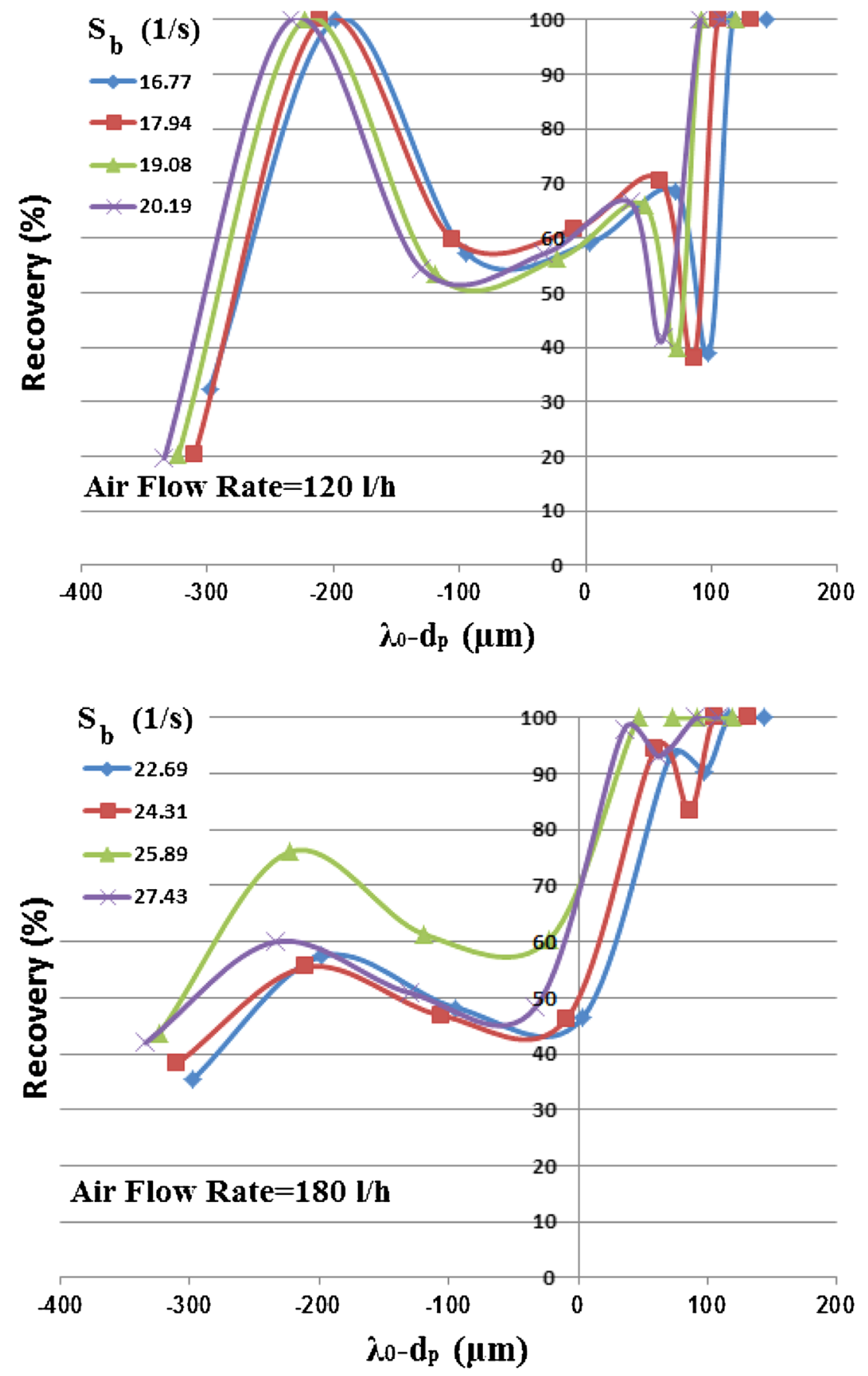

Fig. 1 Flotation recovery of coal particles for different $S_{\mathrm{b}}$ and $\lambda_{\mathrm{p}}$

particle sizes" (Do 2010; Soni 2013; Yoon et al. 2012). The negative correlation $(-0.61)$ between $R$ and $d_{\mathrm{p}}$ could be due to the fact that there are difficulties in floating coarse particles above approximately $149 \mu \mathrm{m}$ (100 mesh), and also ultra-fine particles approximately under $10 \mu \mathrm{m}$. The optimum flotation occurs at the particle sizes in the range of $20-105 \mu \mathrm{m}$.

From the inter-correlation results (Table 2), there is meaningful negative relationship among $R$ and $k$ with particle circularity " $C_{\mathrm{p}}$ " $(r \sim-0.40)$. Results indicated that increasing $C_{\mathrm{p}}$ would lead to a decrease in recovery and $k$. This outcome can be explained by the latest findings that flotation responses (floatability, hydrophobicity, etc.) are driven by the impact of the collector on high energy surface sites (most probably the edges) of the overall particle surface (Guven et al. 2014). Therefore, by increasing $C_{\mathrm{p}}$, floatability and as a result recovery would be decreased. Based on this fact $C_{\mathrm{p}}$ has been selected as another predictor variable. 

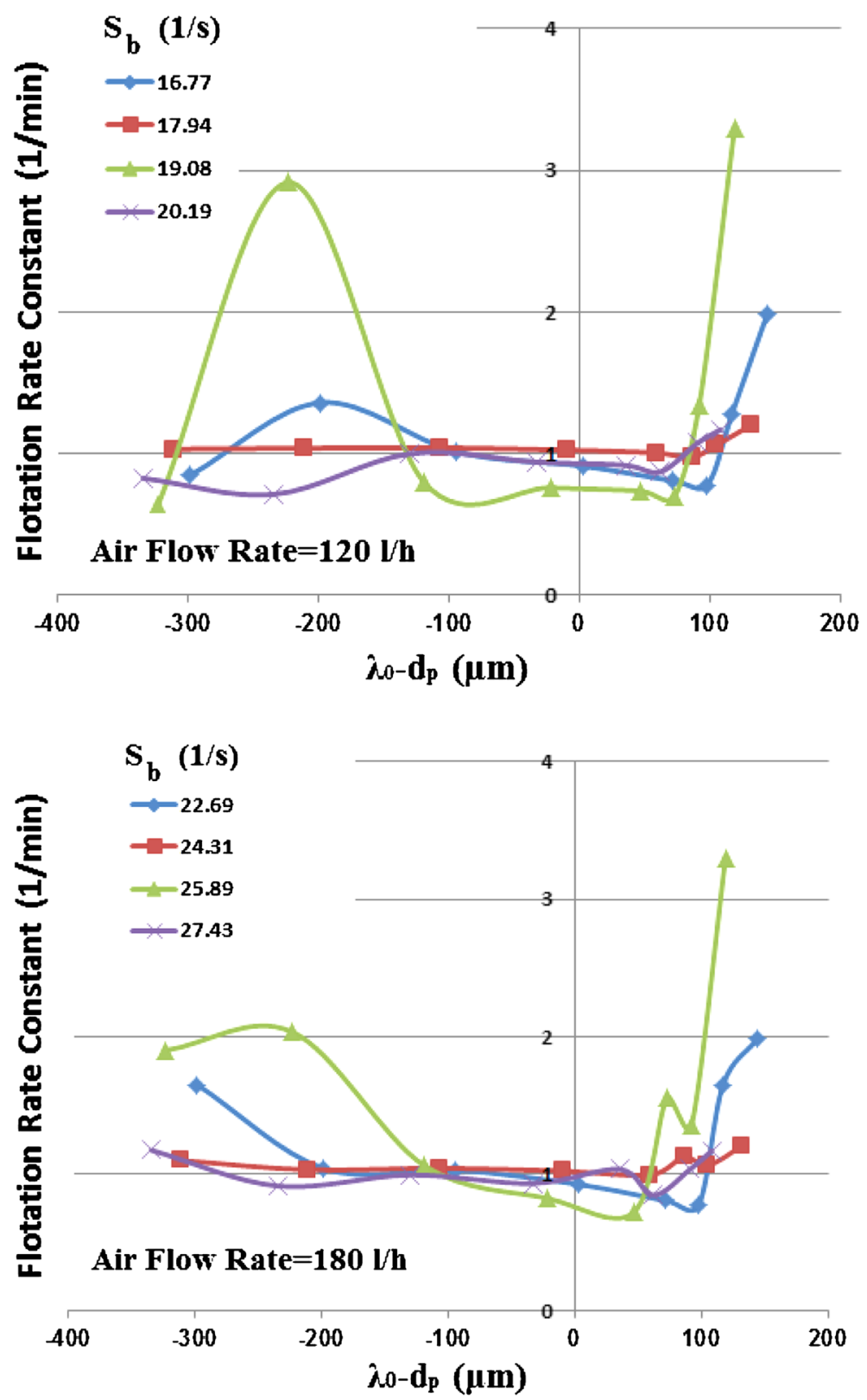

Fig. 2 Flotation rate constant of coal particles for different $S_{\mathrm{b}}$ and $\lambda_{\mathrm{p}}$

Moreover, results (Table 2) show significant correlations among $\varepsilon, R e_{\mathrm{b}}$ and $\lambda_{0}$ (Fig. 4). These relationships can be explained based on Eq. (6). Among these variables, $\varepsilon$ that shows higher inter-correlation with flotation responses was selected although results show there is not a noteworthy $r$ among $\varepsilon$ with $R$ and $k$. Recent investigation also reported that an increase in the energy dissipation rate (c) from 1 to $10 \mathrm{~kW} / \mathrm{m}^{3}$ resulted in a minor change in graderecovery curves (Soni 2013). Positive linear correlation among $S_{\mathrm{b}}$ with $R$ and $k$ based on flotation tests was also observed (Table 2). According to the latest studies: "a rise in the airflow rate increased the recovery at a given particle size" (Soni 2013). Therefore, $S_{\mathrm{b}}$ as a hydrodynamic variable was chosen for the modeling. Additionally, there is a meaningful positive relationship between $R$ and $k$ ( $r$ : 0.37) [which is in a good agreement with the general concept of Eq. (2)].

\subsection{Numerical modeling}

Various linear and non-linear regressions were used to study the potential relationship among selected particle characteristics $\left(d_{\mathrm{p}}\right.$ and $\left.C_{\mathrm{p}}\right)$ and hydrodynamic conditions $\left(\varepsilon\right.$, and $\left.S_{\mathrm{b}}\right)$ with flotation responses $(k$ and $R$ ). Using stepwise multivariable linear regression, the following multivariable equations were developed to describe the possible relationship: 
Table 2 Inter-item correlation between various coal flotation variables with flotation responses $(k$ and $R)$

\begin{tabular}{lcccccccccc}
\hline Variables & $R$ & $k$ & $D_{\mathrm{p}}$ & \multicolumn{1}{c}{$C_{\mathrm{p}}$} & $R e_{\mathrm{p}}$ & $\lambda_{0}$ & $S_{\mathrm{b}}$ & $\lambda_{0}-d_{\mathrm{p}}$ & $R e_{\mathrm{b}}$ & $\varepsilon$ \\
\hline$R$ & 1.000 & 0.37 & -0.61 & -0.40 & -.58 & -0.02 & 0.11 & 0.60 & -0.02 & 0.07 \\
$k$ & 0.37 & 1.000 & -0.08 & -.42 & -0.03 & 0.02 & 0.07 & 0.09 & 0.01 & -0.07 \\
$d_{\mathrm{p}}$ & -0.61 & -0.08 & 1.000 & 0.34 & 0.99 & 0.00 & -.001 & -0.99 & 0.00 & -0.003 \\
$C_{\mathrm{p}}$ & -0.40 & -0.42 & 0.34 & 1.000 & 0.31 & 0.00 & 0.00 & -0.34 & 0.00 & 0.00 \\
$R e_{\mathrm{p}}$ & -0.58 & -0.03 & 0.99 & 0.31 & 1.000 & 0.00 & 0.00 & -0.99 & 0.00 & -0.001 \\
$\lambda_{0}$ & -0.02 & 0.02 & 0.003 & 0.00 & 0.001 & 1.000 & -0.42 & 0.09 & 0.99 & -0.98 \\
$S_{\mathrm{b}}$ & 0.11 & 0.07 & -0.001 & 0.00 & 0.00 & -0.42 & 1.000 & -0.04 & -0.42 & 0.41 \\
$\lambda_{0}-d_{\mathrm{p}}$ & 0.60 & 0.08 & -0.99 & -0.34 & -0.99 & 0.09 & -0.04 & 1.000 & 0.09 & -0.08 \\
$R e_{\mathrm{b}}$ & -0.02 & 0.01 & 0.002 & 0.00 & 0.001 & 0.99 & -0.424 & 0.09 & 1.000 & -0.95 \\
$\varepsilon$ & 0.02 & -0.07 & -0.003 & 0.00 & -0.001 & -0.98 & 0.41 & -0.08 & -0.95 & 1.000 \\
\hline
\end{tabular}

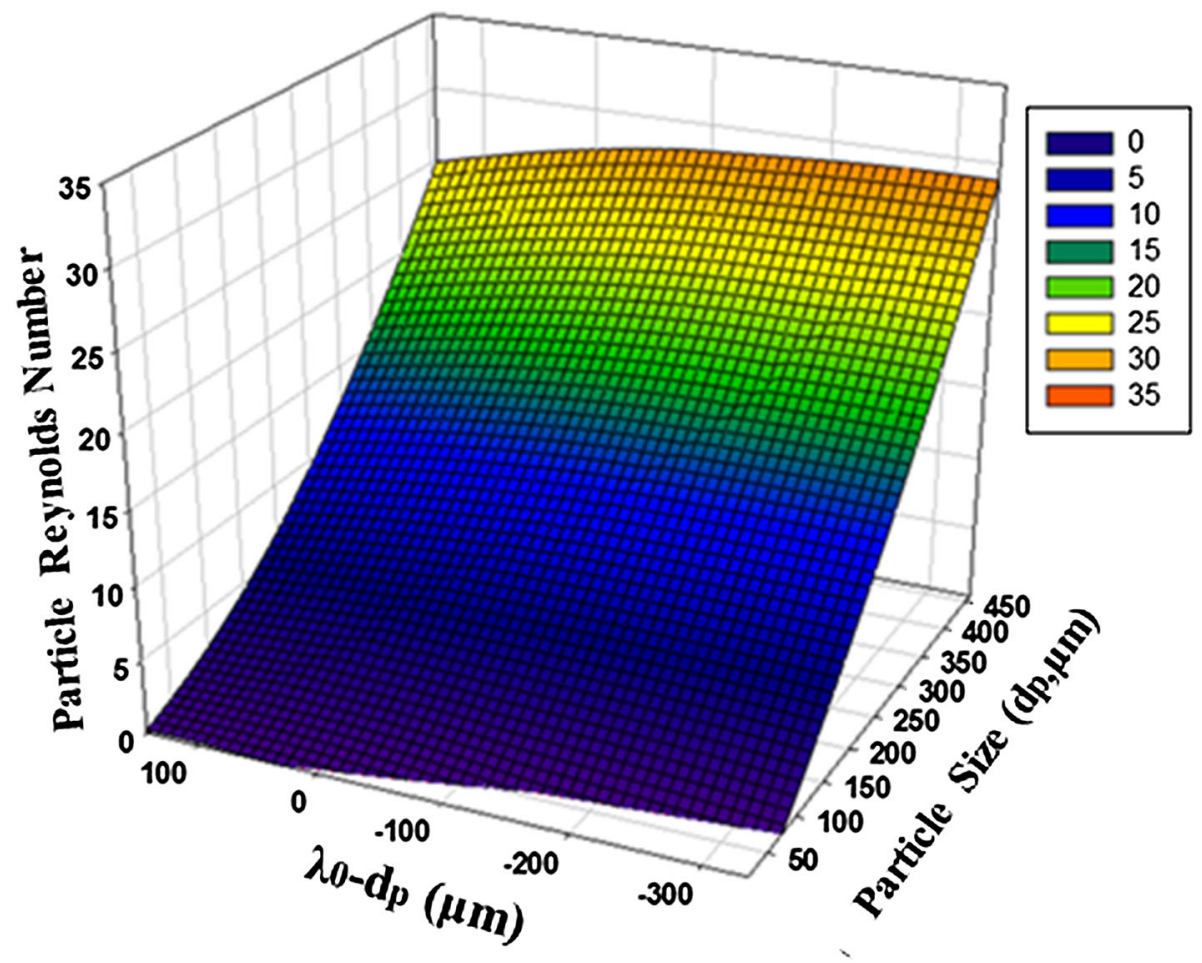

Fig. 3 Relationship among coal particle variables

$$
\begin{aligned}
& R(\%)= 122.427-0.092 d_{\mathrm{p}}-100.428 C_{\mathrm{p}}+0.932 S_{\mathrm{b}} \\
&-0.706 \varepsilon \\
& R^{2}= 0.42 \\
& k(1 / \mathrm{min})= 3.128+0.000249 d_{\mathrm{p}}-4.248 C_{\mathrm{p}}+0.018 S_{\mathrm{b}} \\
& \quad-0.045 \varepsilon \\
& R^{2}=0.2
\end{aligned}
$$

In the stepwise variable selection, variables are sequentially entered into the model. The first variable considered for reflecting into the equation is the one with largest positive or negative correlation with the dependent variable. This variable is entered into the equation only if it satisfies the criterion for entry. The next variable, with the largest partial correlation, is considered as the second equation input. The procedure stops when there are no variables that meet the entry criterion (SPSS 2004). Various nonlinear multivariable regressions have been checked to improve correlation coefficient $\left(R^{2}\right)$ versus linear models. Although nonlinear models indicated [Eqs. (10) and (11)] higher $R^{2}$ compared with linear equations [Eqs. (8) and (9)], the difference between actual 


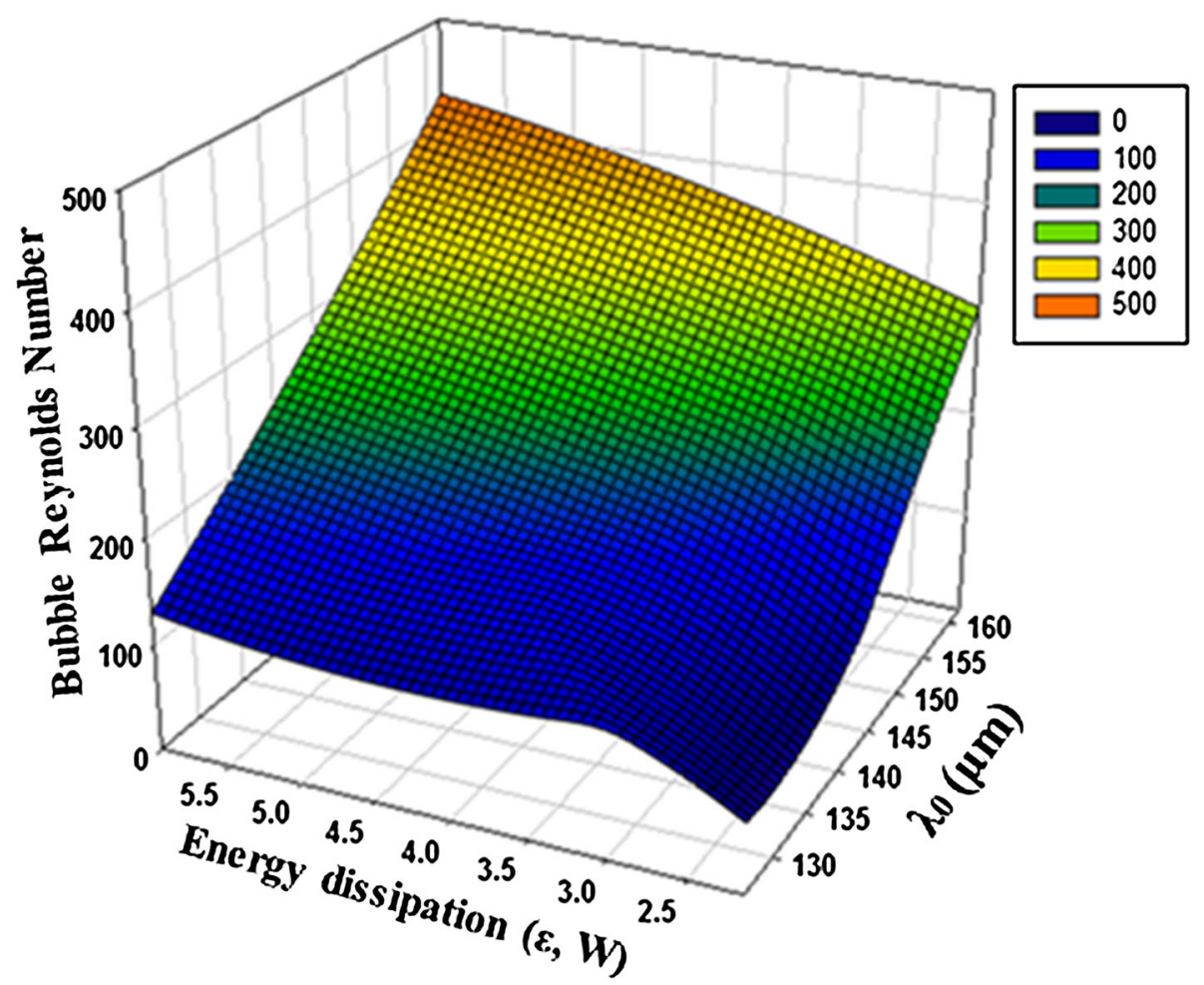

Fig. 4 Relationship among flotation hydrodynamic variables

and predicted value from these equations are not satisfactory for a predictive model (Fig. 5).

$$
\begin{aligned}
R(\%)= & -321.665-1.35 d_{\mathrm{p}}+0.006 d_{\mathrm{p}}^{2}-7.898 e^{-0.006} d_{\mathrm{p}}^{3} \\
& +1783.39 C_{\mathrm{p}}-1753.378 C_{\mathrm{p}}^{2}+0.937 S_{\mathrm{b}}-0.976 \varepsilon \\
R^{2}= & 0.63
\end{aligned}
$$

$$
\begin{aligned}
k(1 / \min )= & 1.497-0.016 d_{\mathrm{p}}+7.586 e^{-0.005} d_{\mathrm{p}}^{2} \\
& -9.41 e^{-0.008} d_{\mathrm{p}}^{3}-1.985 C_{\mathrm{p}}+0.661 \varepsilon \\
& -0.086 \varepsilon^{2}+0.014 S_{\mathrm{b}}
\end{aligned}
$$$$
R^{2}=0.41
$$

\subsection{Soft computing (ANFIS)}

The ANFIS procedures by the same regression inputs were applied to improve predictions of regression models (linear and non-linear). It has been widely established that to model complex relationships, when regression (linear or non-linear) cannot accurately correlate variables, soft computing methodology can effectively be used, as this technique is developed to exploit tolerance for imprecision, uncertainty, and partial truth. From the total database (64) used in the modeling by ANFIS, randomly 50 samples were selected for training phase and 14 data for testing phase. ANFIS in the training phase can be made more efficient by certain preprocessing steps. In this study, all the input and output data in the training phase were preprocessed by normalizing the inputs and targets so that their mean was zero and their standard deviation was 1 :

$N_{\mathrm{p}}=\frac{A_{\mathrm{p}}-m e a n A_{\mathrm{ps}}}{s t d A_{\mathrm{p}}}$

where $A_{\mathrm{p}}$ is the actual parameter, mean $A_{\mathrm{ps}}$ is the mean of the actual parameters, $s t d A_{\mathrm{p}}$ is the standard deviation of the actual parameters, and $N_{\mathrm{p}}$ is the normalized parameter, the input data (Demuth and Beale 2002). Table 3 shows the parameters of the ANFIS models for the prediction of $k$ and $R$ based on the input set $\left(d_{\mathrm{p}}, C_{\mathrm{p}}, S_{\mathrm{b}}\right.$, and $\left.\varepsilon\right)$. After a successful training phase, in testing stage, the correlation coefficients $\left(R^{2}\right)$ of $\mathrm{k}$ and $\mathrm{R}$ for predictions were 0.85 , and 0.99 , respectively. It can be observed that $\mathrm{k}$ and $\mathrm{R}$ prediction using the input set and ANFIS procedure is acceptable and satisfactory (Fig. 5). According to these results, it can be concluded that the proposed ANFIS procedures yield significant predictions of coal flotation responses based on particle characteristics and hydrodynamic conditions, and these soft computing models can be used in the industrial control systems to monitor the froth flotation process of coal particles. 

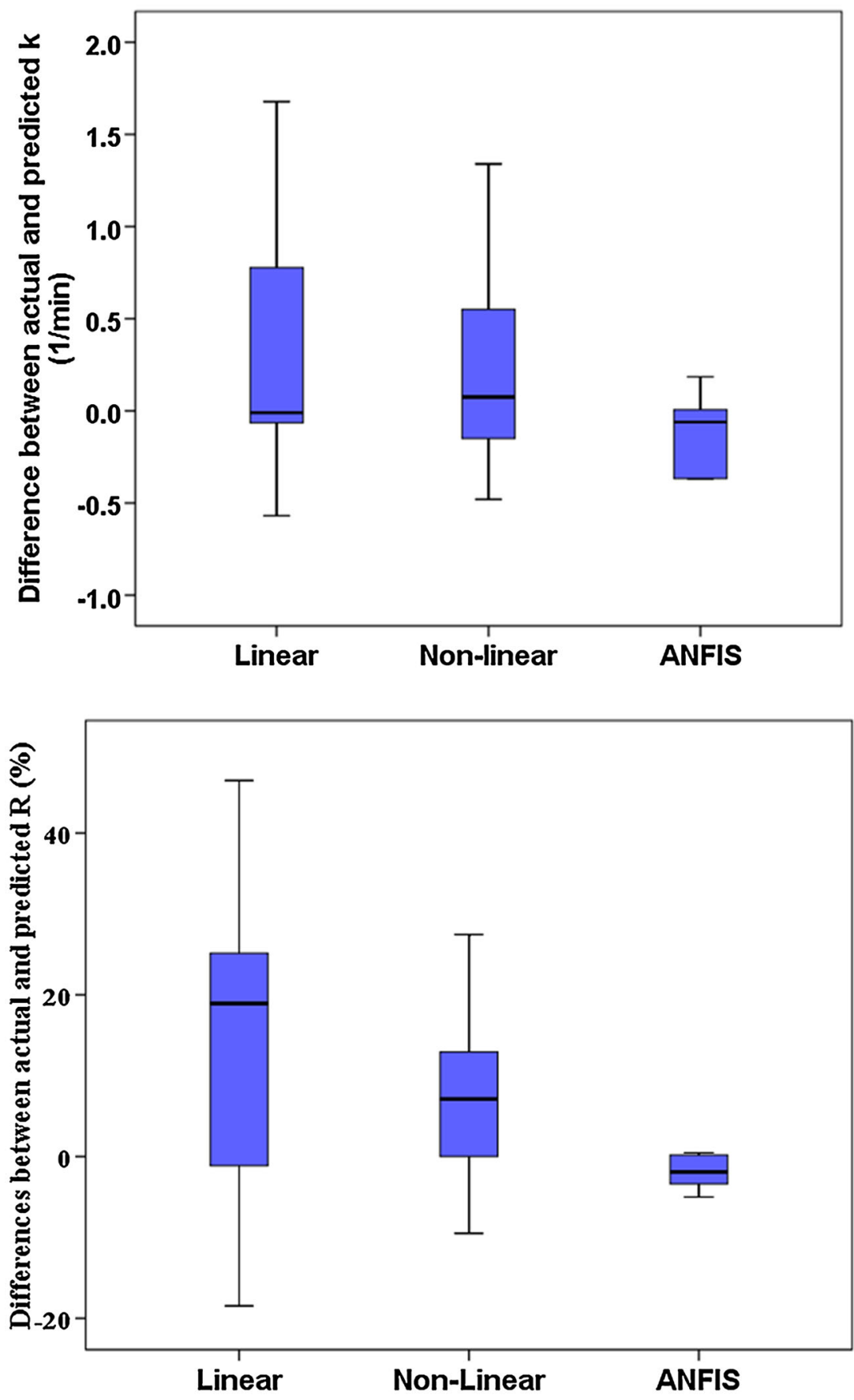

Fig. 5 Differences between actual and predicted $R$ and $k$ by various models

Table 3 Parameters of ANFIS models for prediction of $k$ and $R$ based on various the input set $\left(d_{\mathrm{p}}, C_{\mathrm{p}}, S_{\mathrm{b}}\right.$, and $\left.\varepsilon\right)$

\begin{tabular}{llrlll}
\hline Variable & Radius training & Epoch & SZDR $^{\mathrm{a}}$ & $\mathrm{SZIR}^{\mathrm{b}}$ & $R^{2}$ \\
\hline$k$ & 0.19 & 1000 & 0.95 & 1.1 & 0.85 \\
$R$ & 0.48 & 500 & 0.95 & 1.1 & 0.99 \\
\hline
\end{tabular}

${ }^{a}$ Step size decrease rate

b Step size increase rate

\section{Conclusions}

In the coal industry, flotation continues to be a challenge in many coal preparation plants as operators need to have a sound understanding of the flotation process in order to trouble-shoot and optimize the performance of the whole plant. Conducting a model for the coal flotation would be beneficial to fully understand operations of units, train 
operators and control the whole process. Due to the significant difficulty of integrating complex flotation subprocesses in a model, numerical method in fundamental models has many limitations (considering a long list of variables). This investigation presented a method for variable selection and based on that selection, presented considerable models for the prediction of coal flotation responses (flotation rate constant and recovery). A comprehensive database was prepared with 64 flotation tests under various conditions. Through the database, statistical analyses were performed to select effective variable and to better understand the relationship among particle characteristics (size, particle Reynolds number, micro scale turbulence for particles and circularity) and hydrodynamic conditions (bubble Reynolds number, micro scale turbulence for bubbles, energy dissipation, and bubble surface area flux) with the flotation rate constant and recovery of coal particles.

Based on the statistical analyses four variables have been chosen (size, circularity, energy dissipation, and bubble surface area flux) as inputs for the prediction coal flotation responses. Multivariable regressions were conducted to provide statistical models among inputs with the flotation rate constant and recovery (as outputs). The correlation coefficients of nonlinear models were 0.41 and 0.63 for the flotation rate constant and recovery, respectively (which were not satisfactory). Adaptive network based on fuzzy inference system (ANFIS) models was used to accurately correlate variables. In the ANFIS testing process, models predicted both recovery and flotation rate constant quite satisfactorily. The correlation coefficients between actual and predicted values in testing phase were 0.99 and 0.85 for recovery and flotation rate constant, respectively. From the results, it can be concluded that the method applied and its results can be further used as an expert system in froth flotation to optimize the process parameters and evaluate the parameter interactions for the expected recovery responses.

Open Access This article is distributed under the terms of the Creative Commons Attribution 4.0 International License (http://creative commons.org/licenses/by/4.0/), which permits unrestricted use, distribution, and reproduction in any medium, provided you give appropriate credit to the original author(s) and the source, provide a link to the Creative Commons license, and indicate if changes were made.

\section{References}

Abkhoshk E, Kor M, Rezai B (2010) A study on the effect of particle size on coal flotation kinetics using fuzzy logic. Expert Syst Appl 37:5201-5207

Agar GE, Chia J, Requis-c L (1998) Flotation rate measurements to optimise an operating circuit. Miner Eng 11(4):347-360
Amini E (2012) Influence of flotation cell hydrodynamics on the flotation kinetics and scale up of flotation recovery ( $\mathrm{PhD}$ thesis), The University of Queensland in Sustainable Minerals Institute-Julius Kruttschnitt Mineral Research Centre, pp 1-207

Arnold BJ, Aplan FF (1989) The hydrophobicity of coal macerals. Fuel 68:651-658

Atkinson K (1989) An introduction to numerical analysis. Wiley, Newyork

Barraza J, Guerrero J, Piñeres J (2013) Flotation of refuse tailings fine coal slurry. Fuel Process Technol 106:498-500

Bastian A (2000) Identifying fuzzy models utilizing genetic programming. Fuzzy Set Syst 113:335-350

Buragohain M, Mahanta C (2008) A novel approach for ANFIS modelling based on full factorial design. Appl Soft Comput 8:609-625

Chelgani SC, Makaremi S (2013) Explaining the relationship between common coal analyses and Afghan coal parameters using statistical modeling methods. Fuel Process Technol 110:79-85

Chelgani SC, Shahbazi B, Rezai B (2010) Estimation of froth flotation recovery and collision probability base on dimensional parameters using artificial neural network. Int $\mathbf{J}$ Miner Metall Mater 17(5):526-534

Chelgani SC, Dehghan F, Hower JC (2011a) Estimation of some coal parameters depending on petrographic and inorganic analyses by using Genetic algorithm and adaptive neuro-fuzzy inference systems. Energy Explor Exploit 29(4):479-494

Chelgani SC, Hart B, Grady WC, Hower JC (2011b) Study relationship between inorganic and organic coal analysis with gross calorific value by multiple regression and ANFIS. Int $\mathbf{J}$ Coal Prep Util 31(1):9-19

Demuth H, Beale M (2002) Neural network toolbox for use with MATLAB. The MathWorks Inc., Berkeley, p 154

Do H (2010) Development of a turbulent flotation model from first principles (PhD Thesis), The Virginia Polytechnic Institute and State University, pp 1-117

Dote Y, Ovaska SJ (2001) Industrial applications of soft computing: a review. In: Proceedings of the IEEE, pp 1243-1265

Girgin EH, Do S, Gomez CO, Finch JA (2006) Bubble size as a function of impeller speed in a self-aeration laboratory flotation cell. Miner Eng 19:201-203

Golshani T, Jorjani E, Chelgani SC, Shafaei SZ, Heidari Nafechi Y (2013) Modeling and process optimization for microbial desulphurization of coal by using a two-level full factorial design. Int J Min Sci Technol 23(2):261-265

Gorain BK, Franzidis JP, Manlapig EV (1997) Studies on impeller type, impeller speed and air flow rate in an industrial scale flotation cell. Part 4: effect of bubble surface area flux on flotation kinetics. Miner Eng 10:367-379

Gorain BK, Franzidis JP, Manlapig EV (1998) Studies on impeller type, impeller speed and air flow rate in an industrial scale flotation cell. Part 5: validation of k-Sb relationship and effect of froth depth. Miner Eng 11:615-626

Gui X, Liu J, Cao Y, Cheng G, Li S, Wu L (2014) Flotation process design based on energy input and distribution. Fuel Process Technol 120:61-70

Gupta AK, Banerjee PK, Mishra A (2009) Influence of chemical parameters on selectivity and recovery of fine coal through flotation. Int J Miner Process 92:1-6

Guven O, Ozdemir O, Karaagaclioglu IE, Celik MS (2014) Surface morphologies and floatability of sand blasted quartz particles. Miner Eng 70:1-7

Harris MC (1998) The use of flotation plant data to simulate flotation circuits. Conference on Proceedings of the South African institute of mining and metallurgy, Technikon, South Africa, vol 3-4, pp 1-27 
Hernandez-Aguilar JR, Rao SR, Finch JA (2005) Testing the k-Sb relationship at the microscale. Miner Eng 18:591-598

Hower JC, Frankie KA, Wild GD, Trinkle EJ (1984) Coal microlithotype response to froth flotation in selected western Kentucky coal. Fuel Process Technol 9:1-20

Hower JC, Kuehn KW, Parekh BK, Peters WJ (2000) Maceral and microlithotype beneficiation in column flotation at the powell mountain coal mayflower preparation plant. Fuel Process Technol 67:23-33

$\mathrm{Hu}$ Y, Qiu G, Miller JD (2003) Hydrodynamic interactions between particles in aggregation and flotation. Int $\mathrm{J}$ Miner Process 70:157-170

Huynh L, Kohli I, Osborne D, De Waal H, Walstra C (2011) Design and performance aspect of coal flotation-experiences with the Jameson cell, 1-11. http://www.jamesoncell.com/EN/Down loads/technical\%20papers/Design\%20and\%20performance $\%$ 20 aspects $\% 20$ of $\% 20$ coal $\% 20$ flotation $\% 20 \% 20$ experiences $\% 20$ with $\% 20$ the $\% 20 \mathrm{Jameson} \% 20$

Jang JSR (1993) ANFIS: adaptive-network-based fuzzy inference systems. IEEE Trans Syst Man Cybern 23:665-685

Jang JSR, Sun CT (1995) Neuro-fuzzy modeling and control. Proc IEEE 83:378-406

Jang JSR, Sun CT, Mizutani E (1997) Neuro-fuzzy and soft computing: a computational approach to learning and machine intelligence. Prentice Hall Inc, Upper Saddle River

Jena MS, Biswal SK, Das SP, Reddy PSR (2008) Comparative study of the performance of conventional and column flotation when treating coking coal fines. Fuel Process Technol 89:1409-1415

Jorjani E, Mesroghli Sh, Chelgani SC (2008) Prediction of operational parameters effect on coal flotation using artificial neural network. Int J Miner Metall Mater 15(5):528-533

Jorjani E, Asadollahi Poorali H, Sam A, Chelgani SC, Mesroghli Sh, Shayestehfar MR (2009) Prediction of coal response to froth flotation based on coal analysis using regression and artificial neural network. Miner Eng 22:970-976

Karimi M, Akdogan G, Bradshaw SM (2014) A computational fluid dynamics model for the flotation rate constant, Part I: Model development. Miner Eng 69:214-222

Kayak O, Zadeh LA (1998) Fuzzy inference systems: a critical review, computational intelligence: soft computing and fuzzyneuro integration with applications. Springer, Berlin

King RP (1978) A pilot-plant investigation of a kinetic model for flotation. J S Afr Inst Min Metall 78:325-338

Liang L, Li Z, Peng Y, Tan J, Xie G (2015) Influence of coal particles on froth stability and flotation performance. Miner Eng 81:96-102

Loveday BK, Raghubir S (1995) Design and optimisation of flotation circuits using simulation. In: Proceedings of the SAIMM colloquium on interactions between comminution and downstream processing, Mintek, South Africa, vol 5-6, pp 1-10

Lynch AJ, Johnson NW, Manlapig EV, Thorn CG (1981) Mineral and coal flotation circuits-their simulation and control. Elsevier, Amsterdam, pp 53-56

Mathe ZT, Harris MC, O'conner CT (2000) A review of methods to model the froth phase in non-steady state flotation systems. Miner Eng 13(2):127-140

Neethling SJ, Cilliers JJ (2003) Modelling flotation froths. Int J Miner Process 72(1-4):267-287

Nguyen AV (1998) Particle-bubble encounter probability with mobile bubble surfaces. Int J Miner Process 55(2):73-86

Peng Y, Liang L, Tan J, Sha J, Xie G (2015) Effect of flotation reagent adsorption by different ultra-fine coal particles on coal flotation. Int J Miner Process 142:17-21

Ralston J, Fornasiero D, Hayes R (1999) Bubble-particle attachment and detachment in flotation. Int J Miner Process 56(1):133-164
Rra TC, Govindarajan B, Vanangamudi M (1989) A kinetic model for batch coal flotation. Miner Eng 2(3):403-414

Runge KC, Harris MC, Frew JA, Manlapig EV (1997) Floatability of streams around the Cominco Red Dog Lead cleaning circuit. In: Proceedings of the sixth mill operators' conference, Madang, Papua New Guinea, vol 6-8, pp 157-163

Schubert H (1977) Die Modellierung des Flotations prozesses auf hydrodynamischer. Grundlage-Neue Bergbautechnik 7:446

Schulze HJ (1984a) Physico-chemical elementary processes in flotation: an analysis from the point of view of colloid science including processes engineering considerations. In: Fuerstenau DW (ed) Developments in mineral processing, vol 4. Elsevier, Amsterdam, p 348

Schulze HJ (1984b) Physico-chemical elementary processes in flotation. In: Developments in mineral processing. Elsevier, Amsterdam, p 4

Shahbazi B, Rezai B (2009) The effect of type and dosage of frothers on coarse particles flotation. Iran $\mathrm{J}$ Chem Chem Eng 28(1):95-101

Shahbazi B, Rezai B, Koleini SMJ, Noaparast M (2012) The effect of dimensionless parameters on coal flotation. Int J Coal Prep Util 32(4):157-168

Shahbazi B, Rezai B, Koleini SMJ, Noaparast M (2013a) The effect of bubble surface area flux on flotation efficiency of pyrite particles. Iran J Chem Chem Eng 32(2):109-118

Shahbazi B, Rezai B, Chelgani SC, Koleini SMJ, Noaparast M (2013b) Estimation of diameter and surface area flux of bubbles based on operational conditions by using ANFIS. Int J Min Sci Technol 23(3):343-348

Shahbazi B, Rezai B, Koleini SMJ, Noaparast M (2014) The study of influence of bubble surface area flux on flotation rate constant of coal particles. Geosciences 23:45-52

Sherrell IM (2004) Development of a flotation rate equation from first principles under turbulent flow conditions ( $\mathrm{PhD}$ Thesis), The Virginia Polytechnic Institute and State University, pp 1-104

Shoorehdeli MA, Teshnehlab M, Sedigh AK (2009) Training ANFIS as an identifier with intelligent hybrid stable learning algorithm based on particles warm optimization and extended Kalman filter. Fuzzy Sets Syst 160:922-948

Soni G (2013) Development and validation of a simulator based on a first-principle flotation model (Master thesis), The Virginia Polytechnic Institute and State University, pp 1-58

SPSS, Version 13. SPSS Inc. Help Files (2004)

Sun SC, Zimmerman RE (1950) The mechanism of coarse coal and mineral froth flotation. Trans AIME 187:612-622

Tao D, Li B, Johnson S, Parekh BK (2002) A flotation study of refuse pond coal slurry. Fuel Process Technol 76:201-210

Wills B (2006) Handbook of mineral processing technology, 7th edn. Wiley, New York, pp 267-277

Woodbum ET, Wallin PJ (1984) Decoupled kinetic model for simulation of flotation networks. Trans Inst Min Metall (Sect C Miner Process Extr Metall) 93:C153-C161

Woodbum ET, Kropholler HW, Green JCA, Cramer LA (1976) The utility and limitations of mathematical modelling in the prediction of the properties of flotation networks. In: Fuerstenau MC (ed) Flotation, vol 2. A.M. Gaudin Memorial Volume, AIME, New York, pp 638-674

Yager RR, Zadeh LA (1994) Fuzzy sets neural networks, and soft computing. Thomson Learning, New York

Yoon RH, Kelley K, Do H, Sherrell I, Noble A, Kelles S, Soni G (2012) Development of a flotation simulator based on a first principles model. IMPC 2012, New Dehli, Paper No. 980, pp 1-14 